\title{
Effect of a functional polymorphism in the pre-miR-146a gene on the risk and prognosis of renal cell carcinoma
}

\author{
ZHILONG HUANG ${ }^{1,2^{*}}$, ZHANPENG LU $^{3 *}$, JINGCHANG TIAN $^{4}$, GUANGJIAN WANG $^{5}$ and ZHENLI GAO $^{6}$ \\ ${ }^{1}$ Department of Urology, Shandong Provincial Hospital Affiliated to Shandong University, Jinan, Shandong 250021; \\ ${ }^{2}$ Department of Urology, Lanling County People's Hospital, Lanling, Shandong 277799; ${ }^{3}$ Department of Urology, \\ Jining No. 1 People's Hospital, Jining, Shandong 528000; ${ }^{4}$ Department of Urology, The First Hospital of Qiqihaer, \\ Qiqihaer, Heilongjiang 161000; ${ }^{5}$ Department of Urology, Linyi People's Hospital, Linyi, Shandong 276000; \\ ${ }^{6}$ Department of Urology, Yantai Yuhuangding Hospital, Yantai, Shandong 264000, P.R. China
}

Received September 17, 2014; Accepted May 19, 2015

DOI: $10.3892 / \mathrm{mmr} .2015 .4260$

\begin{abstract}
MicroRNAs (miRNAs) are non-coding RNAs that function as regulators of tumor suppressors and oncogenes. A $\mathrm{G}>\mathrm{C}$ polymorphism (rs2910164) in the miR-146a precursor sequence leads to a functional change associated with a risk for various types of malignancy. The role of this single nucleotide polymorphism in the pathogenesis of renal cell carcinoma (RCC) has not yet been examined. The present study evaluated the association between rs2910164 genotypes and the risk and prognosis of RCC in a population comprised of 421 RCC cases and 432 controls. Unconditional logistic regression was used to estimate odds ratios (OR) and $95 \%$ confidence intervals (CI) for rs2910164 genotypes according to case status. Cox proportional hazards regression modeling was used to estimate hazards ratios and 95\% CIs according to the genotypes among the RCC patients. It was found that the rs2910164 GG and GC genotypes were associated with an increased risk of $\mathrm{RCC}$ only in senior subjects ( $>57$-years old; adjusted $\mathrm{OR}=1.59$, 95\% CI=1.04-2.43). Furthermore, the GC and GG genotypes were associated with a poorer survival rate among patients with RCC compared with the $\mathrm{CC}$ genotype $(\mathrm{P}=0.002)$. In conclusion, the observed association between the GG and GC genotype and poorer survival rate of RCC was at least partially mediated by the decreased expression of miR-146a.
\end{abstract}

Correspondence to: Dr Zhenli Gao, Department of Urology, Yantai Yuhuangding Hospital, 20 Yuhuangding East Road, Yantai, Shandong 264000, P.R. China

E-mail: renalcarcinoma9@163.com

${ }^{*}$ Contributed equally

Key words: microRNA-146a, polymorphism, risk, prognosis, renal cell carcinoma

\section{Introduction}

Renal cell carcinoma (RCC) is a kidney cancer that originates in the lining of the proximal convoluted tubule and is the most common type of kidney carcinoma $(1,2)$. The incidence of RCC varies substantially with respect to ethnicity and gender (1). Although numerous risk factors, including smoking, diabetes, hypertension and family history of malignancy have been identified to be associated with RCC (3-5), only a small proportion of the individuals exposed to these environmental factors develop RCC in their lifetime suggesting that genetic factors may be important in RCC oncogenesis.

MicroRNAs (miRNAs), an abundant class of 22-nucleotide-long non-protein coding RNAs, are initially transcribed from genomic DNA to long primary transcripts (pri-miRNAs) and are then cleaved by nuclear Drosha into 60-70 nucleotides hairpin-shaped precursor RNAs (pre-miRNAs) $(6,7)$. To date, miRNAs are considered to be able to modulate the expression of up to a third of all protein-coding genes by binding to the 3' untranslated region (3'UTR) of target gene messenger RNA (mRNA), causing translational repression and/or mRNA degradation (8). miRNAs have been reported to be involved in the regulation of various biological process, including the cell cycle, differentiation, apoptosis and metastasis (8). Previous studies have demonstrated that single nucleotide polymorphisms (SNP) or mutations in miRNA sequences may affect cancer susceptibility by altering miRNA expression, maturation or miRNA-mRNA interaction $(9,10)$. Aberrant miRNA expression has been consistently reported to be associated with oncogenesis $(11,12)$ and the deregulated expression of miRNAs and their targets may result from functional polymorphisms in the miRNA sequence (13-17).

A functional variant (rs2910164) in the miR-146a precursor has been demonstrated to be able to alter the processing of miR-146a and is associated with various types of cancer, including breast or ovarian cancer, papillary thyroid cancer, hepatocellular cancer, esophageal squamous cell cancer, gastric cancer and prostate cancer (11,15-17). Jazdewski et al (11) reported that the $\mathrm{C}$ allele of $\mathrm{rs} 2910164$ may interfere with the processing of microRNA, leading to a reduction of mature miR-146a and less inhibition of its target genes, including 
tumor necrosis receptor-associated factor $6(T R A F 6)$ and interleukin-1 receptor-associated kinase 1 (IRAKI).

A previous study demonstrated that the expression of miR-146a is significantly elevated in RCC tissue (18). In the present study, potential target genes of miR-146a were computationally searched for by interrogating online miRNA target predicting tool (www.mirdb.org), and inducible nitric oxide synthase (iNOS) was identified as a candidate target gene. iNOS has been validated as a target gene of miR-146a in the mouse RCC cell line RENCA and miR-146a is hypothesized to be involved in the carcinogenesis of RCC by exerting an inhibitory effect on iNOS (19). Nitric oxide synthases (NOS) are a family of enzymes catalyzing the production of nitric oxide (NO) from L-arginine. The inducible isoform, iNOS, is involved in the regulation of cell differentiation, proliferation and immune response (20-22). Several lines of investigation have demonstrated that the expression of iNOS is significantly decreased in RCC compared with normal kidney tissue (23-26).

To the best of our knowledge, there are currently no studies the association between pre-miR-146a polymorphisms and the susceptibility or prognosis of RCC. Based on our knowledge regarding the new polymorphism and biological function of miR-146a, it was hypothesized that the pre-miR-27a polymorphism was associated with RCC susceptibility or prognosis. In order to assess this hypothesis, this particular SNP (rs895819) was genotyped and the association with the risk and prognosis of RCC was assessed in a Chinese population.

\section{Materials and methods}

Patients. In total, 421 patients with histologically confirmed primary RCC and 432 cancer-free controls were recruited at the General Hospital of Jinan Military Region (Jinan, China). All participants were ethnic Han Chinese individuals and were grouped into two subgroups based on histological diagnosis. The Fuhrman scale was used to assess tumor nuclear grade (27). The controls were recruited from individuals in the outpatient departments at the same hospital. The cancer-free controls were frequency matched by gender and age to the cases without an individual history of cancer and family unrelated to the cases. Demographic data and information on known and suspected RCC risk factors were collected through interviewer administered questionnaires. The present study was approved by investigational review committees at Qingdao University (Qingdao, China) and written informed consent was obtained from each participant.

Analysis of hsa-miR-146a and iNOS expression. In total, 82 surgically removed renal tissue samples of different genotypes were collected. Total RNA was isolated using a TRIzol one-step RNA isolation kit (Invitrogen Life Technologies, Carlsbad, CA, USA). miR-146a, iNOS and U6 (as an internal control)-specific cDNA were synthesized from total RNA using gene-specific primers according to the manufacturer's instructions of the TaqMan microRNA assay (Applied Biosystems, Foster City, CA, USA). Relative quantification of target miRNA expression was measured by the $\Delta \Delta$ cycle threshold $(\Delta \Delta \mathrm{Ct})$ method. Each sample was examined in triplicate and the raw data are presented as the relative quantity of target miRNA, normalized to U6.
Genotyping of the miR-146a rs2910164 SNP. Peripheral blood $(5 \mathrm{ml})$ was drawn from each participant and genomic DNA for genotyping was isolated using a DNA extraction kit [Shunhua Bioengineer (Shanghai) Co. Ltd., Shanghai, China]. Nanodrop 1000 spectrophotometer (Thermo Fisher Scientific, Inc., Wilmington, DE, USA) and $0.6 \%$ agarose electrophoresis were used to assess the concentration and purity of the DNA. The genotyping protocol was performed as described previously (11). Briefly, DNA samples were amplified by polymerase chain reaction (PCR; Eppendorf Mastercycler ${ }^{\circledR}$ pro; Eppendorf, Hauppauge, NY, USA) using the following primer set: 5'-ATTTTACAGGGCTGGGAC AG-3' and 5'-TCTTCCAAGCTCTTCAGCAG-3'. The PCR products were purified using a USB ExoSAP-IT purification kit (Affymetrix, London, UK) and then was sent to the core facility for sequencing in both directions with the ABI sequencing system (Applied Biosystems).

Cell survival and proliferation assay. The human RCC cell line A498 was used in the present study and was obtained from ATCC ${ }^{\circledR}$ (Manassas, VA, USA). Untreated or pre-treated cells were cultured in serum-free RPMI-1640 medium (Gibco-BRL, Eggenstein, Germany) for 3 days. To examine cell viability, cells in RPMI-1640 medium were supplemented with 10\% FBS (Gibco-BRL) in 6-well plates for $48 \mathrm{~h}$ and the cell number was counted using the trypan blue exclusion method.

Knockdown of iNOS in RCC cells. A498 cells were cultured until the confluence reached $70-80 \%$ and miR-146a mimics (miR10000449-1-5) and inhibitors (miR30000449-1-10 and iNOS specific siRNA (Q000004843-1-A) were purchased from Guangzhou RiboBio Co., Ltd. (Guangzhou, China). Lipofectamine 2000 (Invitrogen Life Technologies) was used to transfect the small molecules into the A498 cells and the silencing effect was evaluated using quantitative (q)PCR and western blot analysis.

Transwell invasion and migration assay. A Transwell insert invasion assay was performed in 24-well fitted inserts with membranes ( $8 \mathrm{~mm}$ pore size; CoStar, Cambridge, MA, USA). Cell invasion was examined using a polycarbonate membrane cell culture insert (Corning Inc., Corning, NY, USA) coated with growth factor reduced Matrigel (BD Biosciences, Bedford, MA, USA). The treated or untreated cells were placed on top of the wells at a density of $2.5 \times 10^{5}$ cells/well. Invaded cells on the lower surface of the membrane were stained and counted.

Western blot analysis. The target proteins were separated with SDS-polyacrylamide gel electrophoresis and then the proteins were transferred onto a polyvinylidene fluoride membrane followed by being blocked with Tris-buffered saline and Tween $20(10 \mathrm{mM}$ Tris- $\mathrm{Cl} \mathrm{pH} 8.0,150 \mathrm{mM}$ $\mathrm{NaCl}$ and $0.05 \%$ Tween 20) containing 5\% non-fat dry milk powder under room temperature for $1 \mathrm{~h}$. The membrane was then incubated with the rabbit anti-iNOS polyclonal antibody (cat. no. ab3523; Abcam, Cambridge, MA, USA; 1:2,000) at $4^{\circ} \mathrm{C}$ overnight, followed by incubation with horseradish peroxidase-conjugated goat anti-rabbit secondary antibody 
Table I. Distribution of selected variables between renal cell carcinoma cases and control subjects.

\begin{tabular}{|c|c|c|c|}
\hline Variable & Cases $(n=421)$ & Control (n=432) & P-value \\
\hline Gender $(\%)$ & & & 0.521 \\
\hline Male & $264(63)$ & $280(65)$ & \\
\hline Female & $157(37)$ & $152(35)$ & \\
\hline Age (years) & $57.1 \pm 9.9$ & $57.6 \pm 9.2$ & 0.444 \\
\hline Body mass index $\left(\mathrm{kg} / \mathrm{m}^{2}\right)$ & $25.2 \pm 3.2$ & $24.8 \pm 3.4$ & 0.077 \\
\hline Drinking status (\%) & & & 0.338 \\
\hline Yes & $118(28)$ & $134(31)$ & \\
\hline No & $303(72)$ & 298 (69) & \\
\hline Smoking status (\%) & & & 0.010 \\
\hline Yes & $307(73)$ & $280(65)$ & \\
\hline No & $114(27)$ & $152(35)$ & \\
\hline Hypertension (\%) & & & 0.089 \\
\hline Yes & $109(26)$ & $108(25)$ & \\
\hline No & $312(74)$ & $324(75)$ & \\
\hline Diabetes(\%) & & & 0.038 \\
\hline Yes & $68(16)$ & $48(11)$ & \\
\hline No & $353(84)$ & $384(89)$ & \\
\hline \multicolumn{4}{|l|}{ Stage $(\%)$} \\
\hline $\mathrm{I}$ & $142(35)$ & & \\
\hline II & $112(27)$ & & \\
\hline III & $63(14)$ & & \\
\hline IV & $104(24)$ & & \\
\hline
\end{tabular}

(cat. no. ab6721; Abcam; 1:10,000) at room temperature for $2 \mathrm{~h}$. A chemical fluorescence signal was detected using an ECL kit (GE Healthcare, Little Chalfont, Buckinghamshire, UK) according to the manufacturer's instructions. The target bands were densitometrically analyzed and normalized to $\beta$-actin.

Statistical analysis. Fisher's exact $\chi^{2}$ test and Student's t-test were used to compare the frequency distribution of age, gender and smoking status between the cases and controls.

Hardy-Weinberg equilibrium of the genotype frequencies of the controls was assessed by a $\chi^{2}$ goodness-of-fit test. The association between the SNP rs895819 polymorphism and $\mathrm{RCC}$ risk were estimated by computing odds ratios (ORs) and their $95 \%$ confidence intervals (CIs) from unconditional logistic regression analysis with the adjustment for possible confounders.

The Kaplan-Meier method was used to estimate overall survival (OS), defined as the time between study registration and patient mortality. The OS periods were compared with log-rank test. Univariate and multivariate Cox proportional hazard regression analyses were performed to estimate the effect of miR-146a polymorphisms on survival, the expression levels of miR-146 and Notch1 in the presence of other known prognostic factors, including age, gender and smoking status. Analyses were performed using SPSS 19.0 software (SPSS, Inc, Chicago, IL, USA) and $\mathrm{P}<0.05$ was considered to indicate a statistically significant difference.

\section{Results}

A total of 421 RCC patients and 432 healthy controls were recruited in the present study and the demographic characteristics and tumor grading information are presented in Table I. No difference was identified regarding age $(\mathrm{P}=0.444)$, gender $(\mathrm{P}=0.521)$ and drinking status $(\mathrm{P}=0.338)$. RCC patients exhibited a higher body mass index $(\mathrm{BMI} ; \mathrm{P}=0.077)$. Significantly more current smokers, ex-smokers and diabetic patients were found among the RCC patients. Approximately 142 (35\%), 112 (27\%), 63 (14\%) and $104(24 \%)$ patients were in stage I, II, III and IV, respectively (Table I).

Genotype distributions of the pre-miR-146a rs2910164 polymorphism in patients and controls are presented in Table II. Following adjusting for possible confounding factors (age, gender, BMI, smoking status, drinking status, hypertension and diabetes), logistic regression analysis revealed that the pre-miR-146a rs2910164 polymorphism was not associated with $\mathrm{RCC}$ risk (adjusted $\mathrm{OR}=1.28,95 \% \mathrm{CI}=0.94-1.73$ ). However, it was found that the association was significant in senior subjects (adjusted OR=1.59, 95\% CI=1.04-2.43; Table III). Additionally, the association between the pre-miR-146a rs2910164 polymorphism and the clinical characteristics of RCC was also examined, however, no association was noted (data not shown). The present study further evaluated the association between the SNP and the survival rate of RCC patients. As shown in Fig. 1A, participants carrying the rs 2910164 GG/GC genotype had a significantly decreased survival rate compared with the 
Table II. Genotype and allele frequencies of the rs895819 polymorphism among cases and controls and the association with RCC risk.

\begin{tabular}{lccr}
\hline rs2910164 polymorphism & Control $(\mathrm{n}=432)$ & RCC $(\mathrm{n}=421)$ & OR (95\% CI) \\
\hline CC & $129(30 \%)$ & $105(25 \%)$ & 1.00 \\
GC & $234(54 \%)$ & $236(56 \%)$ & $1.24(0.90-1.69)$ \\
GG & $69(16 \%)$ & $80(19 \%)$ & $1.42(0.94-2.15)$ \\
GC/CC & $303(7 \%)$ & $316(75 \%)$ & $1.28(0.94-1.73)$ \\
\hline
\end{tabular}

RCC, renal cell carcinoma; OR, odds ratio; CI, confidence interval.

Table III. Stratification analyses between the genotypes of the rs895819 polymorphism and renal cell carcinoma risk.

\begin{tabular}{|c|c|c|c|c|}
\hline \multirow[b]{2}{*}{ Variable } & \multicolumn{2}{|c|}{ Genotype (case/control) } & \multirow{2}{*}{$\frac{\mathrm{GC} / \mathrm{GG} \text { vs. CC }}{\mathrm{OR}(95 \% \mathrm{CI})}$} & \multirow[b]{2}{*}{ P-value } \\
\hline & $\mathrm{CC}(\mathrm{n} / \%)$ & $\mathrm{GC} / \mathrm{GG}(\mathrm{n} / \%)$ & & \\
\hline Total (case/control) & $105 / 129$ & $316 / 303$ & $0.85(0.64-1.15)$ & 0.316 \\
\hline \multicolumn{5}{|l|}{ Age (years) } \\
\hline$\leq 57$ & 056/060 & $129 / 138$ & $0.99(0.64-1.55)$ & 0.994 \\
\hline$>57$ & $049 / 069$ & $187 / 165$ & $0.62(1.04-2.43)$ & 0.029 \\
\hline \multicolumn{5}{|l|}{ Gender } \\
\hline Male & $059 / 083$ & $205 / 197$ & $0.68(0.46-1.01)$ & 0.053 \\
\hline Female & 046/046 & $111 / 106$ & $0.84(0.52-1.36)$ & 0.495 \\
\hline \multicolumn{5}{|l|}{ Smoking } \\
\hline No & $029 / 053$ & 085/099 & $0.73(0.37-1.09)$ & 0.100 \\
\hline Yes & 075/076 & $231 / 204$ & $0.87(0.60-1.26)$ & 0.466 \\
\hline \multicolumn{5}{|l|}{ Drinking } \\
\hline No & 076/088 & $227 / 210$ & $0.79(0.55-1.14)$ & 0.221 \\
\hline Yes & $029 / 041$ & $089 / 093$ & $0.73(0.42-1.29)$ & 0.287 \\
\hline \multicolumn{5}{|l|}{ Hypertension } \\
\hline Yes & 027/038 & $082 / 070$ & $0.60(0.34-1.09)$ & 0.095 \\
\hline No & 078/091 & $234 / 233$ & $0.85(0.59-1.21)$ & 0.378 \\
\hline \multicolumn{5}{|l|}{ Diabetes } \\
\hline Yes & $017 / 013$ & $050 / 036$ & $0.94(0.40-2.18)$ & 0.888 \\
\hline No & 088/096 & $265 / 288$ & $0.99(0.71-1.39)$ & 0.982 \\
\hline
\end{tabular}

OR, odds ratio; CI, confidence interval.

CC genotype, following adjusting for age, gender and smoking status $(\mathrm{P}=0.002$; Fig. $1 \mathrm{~A})$.

A total of 82 surgically removed RCC renal tissue samples with different rs2910164 genotypes were collected and the frequency distribution of the $\mathrm{CC}, \mathrm{CG}$ and $\mathrm{GG}$ genotypes was found to be 30, 51 and 16, respectively (Fig. 1B). The mRNA expression level of miR-146a was also measured in the 82 patients whose tumor specimens were available and its association with the genetic variant was evaluated. As shown in Fig. 1B, the expression of pre-miR-146a in individuals carrying the rs2910164 GG genotype was comparable with GC, and the expression in the GG and GC genotype groups was significantly higher compared with $\mathrm{CC}$ carriers $(\mathrm{P}<0.001)$. The effect of the rs2910164 C allele on the expression level of miR-146a represented a recessive pattern in the high-grade group. The expression pattern of iNOS was also examined using western blot analysis in the collected 82 RCC patients with different genotypes. The expression of miR-146a was higher and iNOS was lower in the GG/GC group compared with in the CC group (Fig. 1C).

To investigate the mechanism underlying the tumor suppressive effect of miR-146a on RCC, iNOS was computationally identified as a potential target gene of miR-146a, which was subsequently confirmed using a luciferase assay, as shown in Fig. 1D-G. Initially, two potential seed sequences were identified in the 3'-UTR of iNOS as the possible binding sites of miR-146a (Fig. 1D and F). By introducing mutations and comparing the luciferase activities with the wild type (Fig. 1E 
A

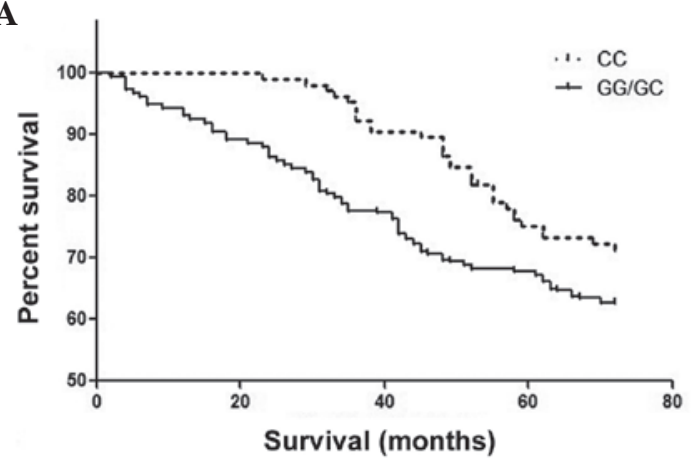

C

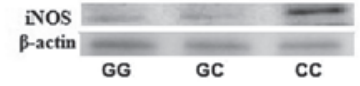

D

$\begin{array}{ll}\text { iNOS 3' UTR WT1 } & \text { 5' TCCCCATGGCCACTTGGGTCTT 3' } \\ \text { miR-146a } & \text { 3' TT I | | | | | } \\ \text { iNOS 3' UTR Mut1 } & \text { 5' TCGGGTACCTAAGTCAAGAGT 5', }\end{array}$

$\mathbf{F}$

$\begin{array}{lc}\text { iNOS 3' UTR WT2 } & \text { 5' TGGCTCCATCCTTAAGTTCTGT 3' } \\ \text { miR-146a } & \text { 3' TTGGGTACCTTAAGTCAAGAGT 5' } \\ \text { iNOS 3' UTR Mut2 } & \text { 5' TGGCTCCATCCAAGTCAAGAGT 3' }\end{array}$

B

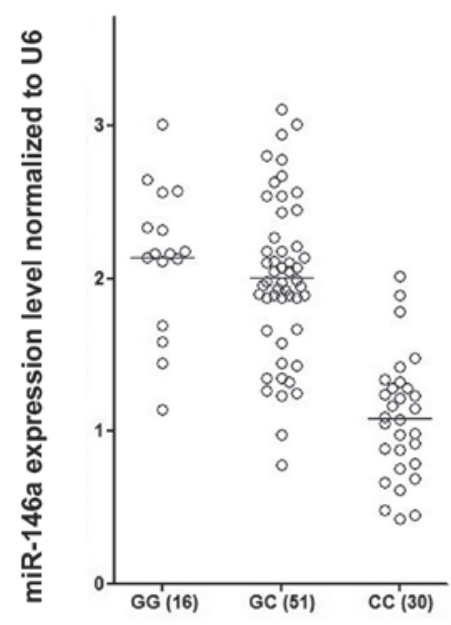

$\mathbf{E}$

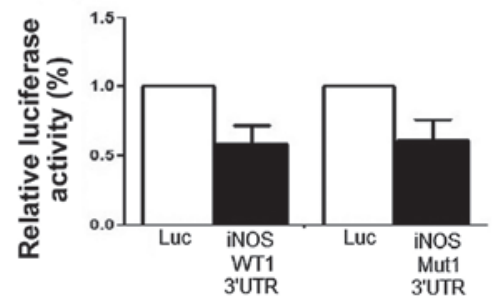

$\mathbf{G}$

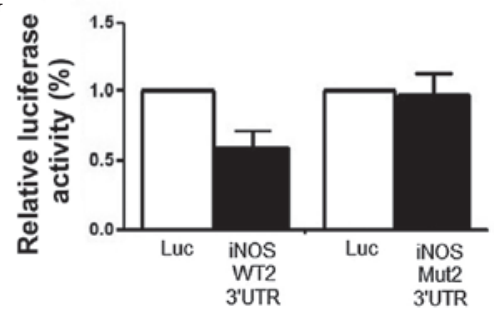

Figure 1. (A) Comparison of the survival rates between $\mathrm{CC}$ and $\mathrm{GG} / \mathrm{GC}$ genotypes. (B) Expression level of mature miR-146a in each genotype group. (C) Protein expression level of iNOS in each genotype group. (D) Schematic comparison of one of the seed sequences in the 3'UTR of iNOS and mature miR-146a. (E) miR-146a could suppress the luciferase activity of WT1 and Mut1. (F) Schematic comparison of the other seed sequences in the 3'UTR of iNOS and mature miR-146a. (G) miR-146a could suppress the luciferase activity of the WT2 sequence, but not Mut2. 3' UTR, 3'-untranslated region; iNOS, inducible nitric oxide synthase; miR-146a, microRNA-146a; WT1, Wilms' tumor 1.

and $\mathrm{F}$ ), the actual binding site of miR-146a in the 3'-UTR of iNOS was located. Furthermore, the effect of miR-146a on cell activities, including proliferation and invasion, and the expression level of iNOS were analyzed by qPCR and western blot analysis. The results demonstrated that overexpression of miR-146a caused significant downregulation of iNOS (Fig. 2A and $\mathrm{B}$ ) and introduction of miR-146a promoted the growth and invasion of RCC cells (Fig. 2C and D). In addition, miR-146a was downregulated by transfection of miR-146a inhibitors. The results demonstrated that downregulation of miR-146a consistently caused significant upregulation of iNOS in RCC cells (Fig. 2E and F) and downregulation of miR-146a suppressed the growth and invasion of RCC cells (Fig. 2G and F).

\section{Discussion}

In the present study, the association between a common polymorphism in miR-146a (rs2910164) and the susceptibility and prognosis of RCC was investigated in a Chinese population composed of 421 RCC patients and 432 control subjects.
Considering low frequencies of the GG genotype and a comparable level of expression for heterozygotes (GC) and homozygotes (GG), suggesting a recessive model, GC and GG genotypes were combined as a recessive genetic model in the following association analysis. The present study found that the rs2910164 GG and GC genotypes were associated with an increased risk of RCC only in senior subjects ( $>57$ years old). Furthermore, the GC and GG genotypes were associated with a poorer survival rate among patients with RCC compared with the $\mathrm{CC}$ genotype.

Accumulative evidence has indicated that miRNAs, which act as tumor suppressors or oncogenes, are involved in numerous important biological processes, including differentiation, proliferation, development and apoptosis $(28,29)$. Polymorphisms in miRNAs have been repeatedly reported to be associated with various types of tumor, including breast cancer, gastric cancer, colorectal cancer and lung cancer (30-33). Jazdzewski et al demonstrated that the C allele of rs2910164 in pre-miR-146a altered the processing and maturation of the miRNA, causing a 1.9-fold reduction of 
A

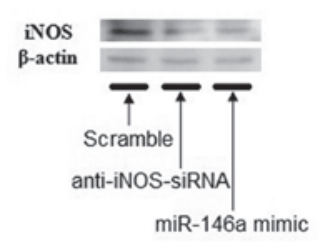

C

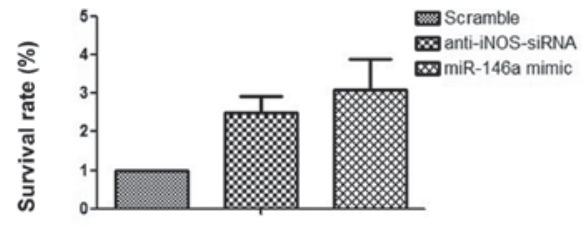

$\mathbf{E}$

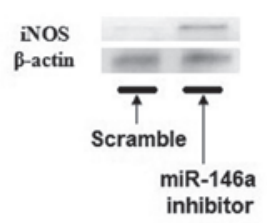

G

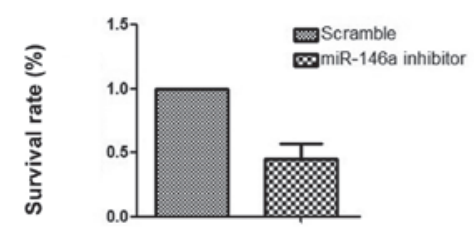

B

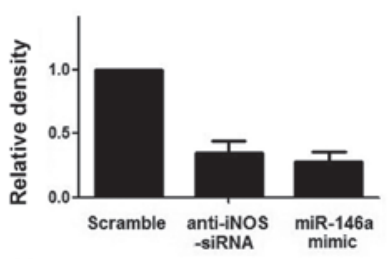

D

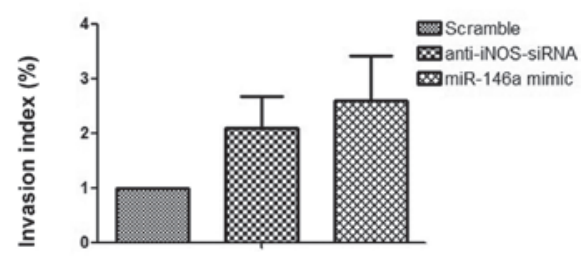

$\mathbf{F}$

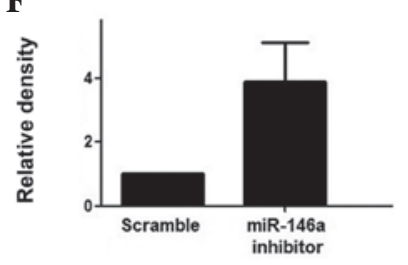

$\mathbf{H}$

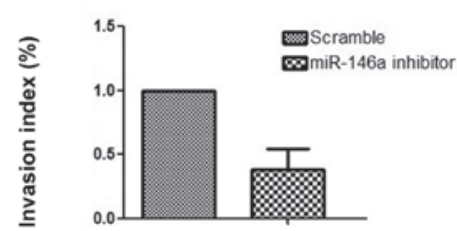

Figure 2. (A) Transfection of miR-146a mimics significantly suppressed the expression of iNOS in RCC cells, which was comparable with the effect of anti-iNOS siRNA. (B) Densitometrically analyzed western blotting results of knockdown of iNOS by miR-146a mimics and anti-iNOS siRNA. (C) Introduction of miR-146a mimics and anti-iNOS siRNA could promote the proliferation of RCC cells. (D) Introduction of miR-146a mimics and anti-iNOS siRNA could promote the migratory capability of RCC cells. (E) Transfection of miR-146a inhibitors significantly enhanced the expression of iNOS in RCC cells. (F) Densitometrically analyzed western blotting results of increased iNOS expression following knockdown of miR-146a. (G) Introduction of miR-146a inhibitors could inhibit the proliferation of RCC cells. $(\mathrm{H})$ Introduction of miR-146a inhibitors could repress the migratory capability of RCC cells. iNOS, inducible nitric oxide synthase; miR-146a, microRNA-146a; RCC, renal cell carcinoma; siRNA, small interfering RNA.

mature miR-146a compared with the G allele (11). The SNP was located at position +60 relative to the first nucleotide on the passenger strand of pre-miR146a, and the C allele was predicted to lead to mispairing within the mature hairpin. Consistently, the mRNA expression level of miR-146a was measured in the 82 patients whose tumor specimens were available and it was found that the expression of pre-miR-146a in those who carried the rs2910164 GG genotype was comparable with GC, and GG and GC genotype groups had a significantly higher expression compared with CC carriers $(\mathrm{P}<0.001)$.

It has been proposed that the rs2910164 genotype contributes to carcinogenesis or tumor suppression by undermining its interactions with key target genes (11). The same group also reported that the $\mathrm{C}$ allele compromised its ability to bind with HeLa cell nuclear protein and also caused inefficient inhibition of the miR146a target genes, including tumor necrosis receptor-associated factor 6 (TRAF6) and interleukin-1 receptor-associated kinase 1 (IRAKI). Jazdewskiet al reported that the GC genotype was associated with an increased risk for papillary thyroid cancer compared with the GC/CC genotypes (11). Permuth-Wey et al reported that the rs2910164 CC/GC genotypes are associated with an increased risk of glioma, particularly among older individuals, and the $\mathrm{C}$ allele was associated with a poorer survival rate among patients with glioblastoma (34). Xu et al found that the rs2910164 CC genotype was associated with a decreased risk for prostate cancer (35). Xu et al found that the GG genotype was associated with an increased risk of hepatocellular carcinoma (36). Guo et al demonstrated that the GG genotype was associated with increased esophageal squamous cell carcinoma risk, particularly among smokers (37). C allele carriers were reported to be susceptible to gastric cancer in a Japanese population (38), while the $\mathrm{C}$ allele was found to be protective against gastric cancer in a Chinese population (24). Inconsistent results of the association between the rs2910164 miR-146a genotype and cancer risk may represent distinct heterogeneous etiology in different tumor types or differences in the ethnicity of investigated populations. The observation that miR-146a was oncogenic in certain types of cancer, but acted as a tumor suppressor in others indicated the miR-146a may target different genes in different types of cancer. As it has been reported that the expression of miR-146a was significantly elevated in RCC (19), it is plausible to hypothesize that miR-146a targets a tumor suppressor in the development of RCC. 
NOS are a family of enzymes catalyzing the production of NO from L-arginine. The inducible isoform, iNOS, is involved in the regulation of cell differentiation, proliferation and immune responses (20-22). Several lines of investigation have demonstrated a significantly decreased expression of iNOS in RCC compared with normal kidney tissue $(19,23,24)$. Similarly, the NOS activity was higher in non-malignant kidney tissue than in RCC tissue and was inversely correlated with tumor grade. Furthermore, cytokine treatment induced a marked increase in NOS activity and NO exerted cytostatic effects on cultured proximal tubular cells and RCC cell lines (25). Consistently, interferon $\gamma$-induced iNOS can inhibit the proliferation of murine RCC cells (26) and the infection of human renal cancer cells by retroviruses harboring the murine iNOS gene can induce the production of high levels of NO, which is associated with autocytotoxicity, suppression of tumorigenicity and abrogation of metastasis (24). In the present study, iNOS was identified as a validated target of miR-146a and introduction of miR-146a promoted the growth and invasion of RCC cells. Overexpression of miR-146a simultaneously caused significant downregulation of iNOS. In addition, miR-146a was downregulated by transfection of miR-146a inhibitors and the results demonstrated that downregulation of miR-146a suppressed the growth and invasion of RCC cells, and downregulation of miR-146a consistently caused significant upregulation of iNOS in RCC cells. The expression pattern of miR-146a and iNOS was also examined in 82 tissue samples collected from RCC patients, which was further compared between the GG/GC than CC group. The results revealed that the expression level of miR-146a was higher and the expression of iNOS was lower in the GG/GC than in the CC group, suggesting the tumor suppressive effect of miR-146a in RCC was mediated by its inhibitory effect on the expression of iNOS.

Although our findings suggest that the pre-miR-146a rs2910164 polymorphism genotypes were associated with a higher risk of RCC, the complex nature of RCC also suggests that this disorder is likely to exhibit genetic characteristics similar to those of other complex disorders heterogeneously affected by variants at multiple gene loci. Further, larger and preferably prospective studies are warranted to validate the role of this polymorphism in the development of RCC. Since polymorphisms often vary in different ethnic populations, additional investigations are also required to verify the association of this polymorphism with RCC risk in diverse ethnic groups.

\section{References}

1. Chow WH, Dong LM and Devesa SS: Epidemiology and risk factors for kidney cancer. Nat Rev Urol 7: 245-257, 2010.

2. Jemal A, Siegel R, Ward E, Hao Y, Xu J and Thun MJ: Cancer Statistics, 2009. CA Cancer J Clin 59: 225-249, 2009.

3. Calle EE and Kaaks R: Overweight, obesity and cancer: Epidemiological evidence and proposed mechanisms. Nat Rev Cancer 4: 579-591, 2004

4. Setiawan VW, Stram DO, Nomura AM, Kolonel LN and Henderson BE: Risk factors for renal cell cancer: The multiethnic cohort. Am J Epidemiol 166: 932-940, 2007.

5. Zeegers MP, Tan FE, Dorant E and van den Brandt PA: The impact of characteristics of cigarette smoking on urinary tract cancer risk: A meta-analysis of epidemiologic studies. Cancer 89: $630-639,2000$
6. Lee Y, Jeon K, Lee JT, Kim S and Kim VN: MicroRNA maturation: Stepwise processing and subcellular localization. EMBO J 21: 4663-4670, 2002.

7. Lee Y, Ahn C, Han J, Choi H, Kim J, Yim J, Lee J, Provost P, Rådmark O, Kim S and Kim VN: The nuclear RNase III Drosha initiates microRNA processing. Nature 425: 415-419, 2003.

8. Calin GA and Croce CM: MicroRNA signatures in human cancers. Nat Rev Cancer 6: 857-866, 2006.

9. Ryan BM, Robles AI and Harris CC: Genetic variation in microRNA networks: The implications for cancer research. Nat Rev Cancer 10: 389-402, 2010.

10. Yang Q, Jie Z, Ye S, Li Z, Han Z, Wu J, Yang C and Jiang Y: Genetic variations in miR-27a gene decrease mature miR-27a level and reduce gastric cancer susceptibility. Oncogene 33: 193-202, 2014

11. Jazdzewski K, Murray EL, Franssila K, Jarzab B, Schoenberg DR and de la Chapelle A: Common SNP in pre-miR-146a decreases mature miR expression and predisposes to papillary thyroid carcinoma. Proc Natl Acad Sci USA 105: 7269-7274, 2008.

12. Turner JD, Williamson R, Almefty KK, Nakaji P, Porter R, Tse V and Kalani MY: The many roles of microRNAs in brain tumor biology. Neurosurg Focus 28: E3, 2010.

13. Duan R, Pak C and Jin P: Single nucleotide polymorphism associated with mature miR-125a alters the processing of pri-miRNA. Hum Mol Genet 16: 1124-1131, 2007.

14. Chae YS, Kim JG, Lee SJ, Kang BW, Lee YJ, Park JY, Jeon HS, Park JS and Choi GS: A miR-146a polymorphism (rs2910164) predicts risk of and survival from colorectal cancer. Anticancer Res 33: 3233-3239, 2013.

15. Chen L, Zhang R, Li P, Liu Y, Qin K, Fa ZQ, Liu YJ, Ke YQ and Jiang XD: P53-induced microRNA-107 inhibits proliferation of glioma cells and down-regulates the expression of CDK6 and Notch-2. Neurosci Lett 534: 327-332, 2013.

16. Zhang X, Chen T, Zhang J, Mao Q, Li S, Xiong W, Qiu Y, Xie Q and Ge J: Notch1 promotes glioma cell migration and invasion by stimulating $\beta$-catenin and $\mathrm{NF}-\kappa \mathrm{B}$ signaling via AKT activation. Cancer Sci 103: 181-190, 2012.

17. Mei J, Bachoo R and Zhang CL: MicroRNA-146a inhibits glioma development by targeting Notch1. Mol Cell Biol 31: 3584-3592, 2011

18. Ha E, Bang JH, Son JN, Cho HC and Mun KC: Carbamylated albumin stimulates microRNA-146, which is increased in human renal cell carcinoma. Mol Med Rep 3: 275-279, 2010.

19. Perske C, Lahat N, Sheffy Levin S, Bitterman H, Hemmerlein B and Rahat MA: Loss of inducible nitric oxide synthase expression in the mouse renal cell carcinoma cell line RENCA is mediated by microRNA miR-146a. Am J Pathol 177: 2046-2054, 2010.

20. MacMillan-Crow LA, Crow JP, Kerby JD, Beckman JS and Thompson JA: Nitration and inactivation of manganese superoxide dismutase in chronic rejection of human renal allografts. Proc Natl Acad Sci USA 93: 11853-11858, 1996.

21. Williams MS, Noguchi S, Henkart PA and Osawa Y: Nitric oxide synthase plays a signaling role in TCR-triggered apoptotic death. J Immunol 161: 6526-6531, 1998.

22. Brito C, Naviliat M, Tiscornia AC, Vuillier F, Gualco G, Dighiero G, Radi R and Cayota AM: Peroxynitrite inhibits $\mathrm{T}$ lymphocyte activation and proliferation by promoting impairment of tyrosine phosphorylation and peroxynitrite-driven apoptotic death. J Immunol 162: 3356-3366, 1999.

23. Renaudin K, Denis MG, Karam G, Vallette G, Buzelin F, Laboisse CL and Jarry A: Loss of NOS1 expression in high-grade renal cell carcinoma associated with a shift of $\mathrm{NO}$ signalling. Br J Cancer 90: 2364-2369, 2004.

24. Juang SH, Xie K, Xu L, Shi Q, Wang Y, Yoneda J and Fidler IJ: Suppression of tumorigenicity and metastasis of human renal carcinoma cells by infection with retroviral vectors harboring the murine inducible nitric oxide synthase gene. Hum Gene Ther 9: 845-854, 1998 .

25. Jansson OT, Morcos E, Brundin L, Bergerheim US, Adolfsson J and Wiklund NP: Nitric oxide synthase activity in human renal cell carcinoma. J Urol 160: 556-560, 1998.

26. Tate DJ Jr, Patterson JR, Velasco-Gonzalez C, Carroll EN, Trinh J, Edwards D, Aiyar A, Finkel-Jimenez B and Zea AH: Interferon-gamma-induced nitric oxide inhibits the proliferation of murine renal cell carcinoma cells. Int J Biol Sci 8: 1109-1120, 2012. 
27. Ficarra V, Martignoni G, Maffei N, Brunelli M, Novara G, Zanolla L, Pea M and Artibani W: Original and reviewed nuclear grading according to the Fuhrman system: A multivariate analysis of 388 patients with conventional renal cell carcinoma. Cancer 103: 68-75, 2005.

28. Bartels CL and Tsongalis GJ: MicroRNAs: Novel biomarkers for human cancer. Clin Chem 55: 623-631, 2009.

29. Harfe BD: MicroRNAs in vertebrate development. Curr Opin Genet Dev 15: 410-415, 2005.

30. Gao LB, Bai P, Pan XM, Jia J, Li LJ, Liang WB, Tang M, Zhang LS, Wei YG and Zhang L: The association between two polymorphisms in pre-miRNAs and breast cancer risk: A meta-analysis. Breast Cancer Res Treat 125: 571-574, 2011.

31. Peng S, Kuang Z, Sheng C, Zhang Y, Xu H and Cheng Q: Association of microRNA-196a-2 gene polymorphism with gastric cancer risk in a Chinese population. Dig Dis Sci 55: 2288-2293, 2010.

32. Zhu L, Chu H, Gu D, Ma L, Shi D, Zhong D, Tong N, Zhang Z and Wang M: A functional polymorphism in miRNA-196a2 is associated with colorectal cancer risk in a Chinese population. DNA Cell Biol 31: 350-354, 2012.

33. Hu Z, Chen J, Tian T, Zhou X, Gu H, Xu L, Zeng Y, Miao R, Jin G $\mathrm{Ma} \mathrm{H}$, et al: Genetic variants of miRNA sequences and non-small cell lung cancer survival. J Clin Invest 118: 2600-2608, 2008.
34. Permuth-Wey J, Thompson RC, Burton Nabors L, Olson JJ, Browning JE, Madden MH, Ann Chen Y and Egan KM: A functional polymorphism in the pre-miR-146a gene is associated with risk and prognosis in adult glioma. J Neurooncol 105: 639-646, 2011.

35. Xu B, Feng NH, Li PC, Tao J, Wu D, Zhang ZD, Tong N, Wang JF, Song NH, Zhang W, et al: A functional polymorphism in Pre-miR-146a gene is associated with prostate cancer risk and mature miR-146a expression in vivo. Prostate 70: 467-472, 2010.

36. Xu T, Zhu Y, Wei QK, Yuan Y, Zhou F, Ge YY, Yang JR, Su H and Zhuang SM: A functional polymorphism in the miR-146a gene is associated with the risk for hepatocellular carcinoma. Carcinogenesis 29: 2126-2131, 2008.

37. Guo H, Wang K, Xiong G, Hu H, Wang D, Xu X, Guan X, Yang K and Bai Y: A functional variant in microRNA-146a is associated with risk of esophageal squamous cell carcinoma in Chinese Han. FAM Cancer 9: 599-603, 2010.

38. Okubo M, Tahara T, Shibata T, Yamashita H, Nakamura M, Yoshioka D, Yonemura J, Kamiya Y, Ishizuka T, Nakagawa Y, et al: Association study of common genetic variants in pre-microRNAs in patients with ulcerative colitis. J Clin Immunol 31: 69-73, 2011. 